\title{
Comer e beber: metáforas apocalípticas de juízo e restauração
}

VANDERLEI DORNELES ${ }^{1}$

— ste artigo analisa as metáforas "comer" e "beber" no contexto bíblico, Ccom ênfase no Apocalipse. Considera que metáforas, mais que simples elementos de linguagem, funcionam como instrumentos estruturantes do pensamento, permitindo compreender as coisas abstratas por meio daquelas mais familiares. O estudo parte da premissa de que os ritos de comensalidade no mundo bíblico marcam importantes eventos de sociabilidade, pactuação e pertencimento. A atitude de comer alimentos sacrificados aos ídolos retrata rompimento das relações com Deus, ao mesmo tempo que o cear com Jesus aponta para a reconstrução das relações quebradas pelo pecado. A visão dos remidos com pleno acesso aos frutos da árvore da vida, por sua vez, retrata a completa restauração das relações entre Deus e sua criação.

Palavras-chave: Metáfora; Comida; Bebida; Juízo; Restauração; Apocalipse.

\section{Eating and drinking: apocalyptic metaphors of judgment and restauration}

1 Doutor em Ciências pela Escola de Comunicação e Artes (USP), doutorando em Ciências da Religião na Universidade Metodista de São Paulo. Professor da Faculdade de Teologia (FAT), do Centro Universitário Adventista de São Paulo (Unasp). E-mail: vanderlei.dorneles@unasp.edu.br 
"This article analyzes the metaphors about "eating" and "drinking" in the biblical context, with an emphasis on the book of Revelation. It considers that metaphors, more than simple elements of language, work as structuring instruments of thought, allowing to understand abstract things through those more familiar. The study starts from the premise that commensal rites in the biblical world mark important events of sociability, compromise, and belonging. The attitude of eating food sacrificed to idols portraits the breaking of relationship with God, while to have a supper with Jesus points to a rebuilding of relations broken by sin. The view of saved with full access to the tree of life's fruits, in turn, portrays the complete restoration of the relationship between God and his creation.

Keywords: Metaphor; Food; Drink; Judgment; Restoration; Revelation.

\section{Introdução}

O leitor percebe a importância das metáforas "comida" e "bebida" logo no início do texto do Apocalipse, que se estendem até o final do livro. Nas promessas à igreja de Éfeso, Jesus diz: "Ao vencedor dar-lhe-ei que se alimente da árvore da vida que se encontra no paraíso de Deus" (Ap 2:7). À Laodiceia, ele retoma a metáfora: "Eis que estou à porta e bato; se alguém ouvir a minha voz e abrir a porta, entrarei em sua casa, cearei com ele, e ele comigo" (Ap 3:20).

Em linguagem de juízo, é dito que aquele que recebe a marca da besta também "beberá do vinho da cólera de Deus, preparado sem mistura no cálice da sua ira” (Ap 14:8, 10). A Babilônia recebe merecidos juízos porque "todas as nações têm bebido do vinho do furor da sua prostituição" (Ap 18:3). Ao final do livro, a metáfora é retomada em linguagem positiva, como nas cartas às igrejas: "De uma a outra margem do rio, está a árvore da vida, que produz doze frutos [...] e as folhas da árvore são para a cura dos povos" (Ap 22:1).

Assim, as metáforas de comida e bebida são bastante comuns na narrativa apocalíptica. Mas isso não é novidade nas Escrituras. De fato, no livro de Gênesis, comer e beber são atividades bastante enfatizadas. Após prover comida para os seres criados (Gn 1:29, 30; 2:9), Deus proíbe alimentar-se da árvore do conhecimento do bem e do mal (3:1-3). 
Por sua vez, Adão e Eva perdem o paraíso por comer dessa árvore proibida $(\mathrm{Gn} 3: 11,22)$. Após o pecado, Adão comerá do "suor" do seu rosto (Gn 3:17-19). Abel e Caim apresentam ofertas de alimentos perante o Senhor (Gn 4:1-4). Mais tarde, Deus manda Noé levar comida para ele e a família na arca, no dilúvio (Gn 6:21). Quando sai da arca, Noé faz sacrifício de animais e aves (Gn 8:20). Deus autoriza ele e sua família a se alimentarem de carne, mas sem o sangue (Gn 9:1-5). Em seguida, Noé bebe vinho e se embriaga (Gn 9:20, 21). MacDonald (2008, p. 2, tradução livre) afirma que, de fato, "há poucas páginas no Antigo Testamento em que alimento não é mencionado", seja como metáfora ou como simples descrição das atividades básicas da vida humana.

Diante dessa predominância da metáfora e das descrições envolvendo comida e bebida nas Escrituras, torna-se bastante relevante considerar que sentidos essa linguagem produz ao ser empregada para transmitir a mensagem apocalíptica. Este artigo tem o objetivo de analisar o emprego de tais metáforas no texto do Apocalipse, a partir da perspectiva de juízo e restauração. A questão a que se propõe a pesquisa é: como as metáforas "comer" e "beber" nos ajudam a entender as mensagens comunicadas pelo profeta no contexto de uma sociedade agrícola marcada pela luta da sobrevivência física? O estudo é feito a partir dos conceitos de metáfora, compreendidos por Lakoff e Johnson (2003). $\mathrm{Na}$ leitura e interpretação dos textos também se emprega o conceito de intertextualidade como um mecanismo de referenciação da mensagem apocalíptica nos textos do Antigo Testamento.

\section{Metáfora e compreensão da realidade}

$\mathrm{Na}$ visão tradicional, as metáforas são apenas elementos de linguagem. Porém, Lakoff e Johnson (2003, p. 54) propõem que elas exercem uma função mais conceitual do que se pensava. Para eles, as metáforas funcionam como instrumentos que "estruturam o sistema conceitual das culturas". Eles explicam que a essência da metáfora é "compreender e experimentar uma coisa em termos de outra" (LAKOFF; JOHNSON, 2003, p. 6). Ou seja, quando a mente é desafiada diante de um objeto que escapa a nossos

2 Texto original: “There is scarcely a page in the Old Testament where food is not mentioned". 
conceitos mais familiares, recorremos à metáfora, empregando imagens de coisas conhecidas para mediar nossa relação com o desconhecido.

Nesse processo, o abstrato ou desconhecido é entendido ou definido a partir daquilo que é familiar. Assim, "as metáforas são conceituais" e funcionam como recursos para "compreensão", exercendo um papel central na "construção da realidade social e política" (LAKOFF; JOHNSON, 2003, p. 160). Elas nos ajudam, principalmente, no que "não podemos compreender totalmente: os sentimentos, a experiência estética, práticas morais e consciência espiritual" (LAKOFF; JOHNSON, 2003, p. 194).

Desta forma, elas se tornam instrumentos mediadores da relação com o desconhecido e podem direcionar a compreensão do mesmo. Nesse caso, as metáforas são capazes de revelar, senão de modelizar nossa compreensão da realidade. Quando, por exemplo, o apóstolo Paulo afirma que "o corpo é o templo do Espírito" (1Co 6:19), ele está expressando um sistema cultural em que o corpo exerce uma função sagrada. Porém, quando uma religião propõe que "o corpo é a prisão do espírito", outra visão de mundo é colocada em debate. Uma terceira visão, ou mesmo um paradigma, é expresso por outra metáfora: "O corpo é uma máquina, e as mitocôndrias são eficientes usinas”. Assim, três diferentes sistemas culturais (cristianismo bíblico, platonismo e modernismo) são nomeados com essas metáforas. Para usar a linguagem de Lakoff e Johnson (2003), essas metáforas não apenas são elementos de linguagem, mas instrumentos que expressam ou estruturam um sistema cultural.

Ao considerar as atividades de comensalidade, tão comuns no mundo antigo, Garcia (2007, p. 22) afirma que "as práticas que envolvem alimentação não só organizam a relação com o sagrado e com os demais membros do grupo, como também apresentam um caráter estruturante da religião", a exemplo das metáforas. Nesse caso, as figuras de linguagem envolvendo comida e bebida não só atribuem um sentido cultural a essas atividades, mas chegam a estruturar a compreensão dos fenômenos religiosos.

Assim, a comida pode funcionar como mecanismo "iniciador, mantenedor ou destruidor" da socialidade e do companheirismo entre as pessoas, ou entre as pessoas e sua religião (GARCIA, 2007, p. 24). Em vista disso, Lévi-Strauss (1969, p. 62) considera que "comida não é algo tão bom para comer quanto é para pensar".

Mounce (1997, p. 114) diz que, no contexto bíblico da cultura oriental, "o compartilhar de uma refeição comum indicava fortes laços de afeição e companheirismo”. MacDonald (2008, p. 4, tradução livre) 
acrescenta que uma pressuposição-chave do antigo semitismo era que "aqueles que comiam e bebiam juntos eram por este mesmo ato ligados um ao outro pelos laços de amizade e obrigações mútuas" ${ }^{3}$. Assim, os textos bíblicos que retratam o selamento de "um pacto pelo ato comunal de comer e beber" trazem a "marca desta ideia semítica primitiva"4. Klingbeil (2004, p. 139) enfatiza que, em contraste com a sociedade utilitarista do século 21, “comer' e 'beber' no Antigo Oriente Médio e no Antigo Testamento tinham importantes funções, distantes da mera satisfação rápida, impessoal e pragmática das necessidades físicas”.

Nessa perspectiva, os textos bíblicos em que as atividades de comensalidade são descritas podem produzir sentidos bem mais amplos do que o de simples atividades de subsistência.

\section{Comida e bebida no texto bíblico}

Uma leitura introdutória aos textos bíblicos que empregam descrições de comida e bebida indica que essas atividades são empregadas com pelo menos três sentidos principais. Em sentido literal, a comida provê o sustento físico (Gn 47:24; 1Sm 28:20). Em sentido simbólico, a comida é usada para celebrar aliança (Gn 26:28-30; 31:54; Êx 18:12; 24:9-11). Há comida como parte de celebração e festa ao Senhor no templo (Dt 12:6-7, $11,12)$. A sabedoria convida para comer pão e beber vinho, e Jesus, para beber a água da vida ( $\mathrm{Pv}$ 9:5; Jo 7:37). Os sentimentos de dor e tristeza são motivo de jejum, para não comer (2Sm 12:16, 17; Dn 6:18; At 9:8), ao passo que alegria é motivo para festa e comida (Is 25:1, 6; Lc 15:22-24).

Em terceiro lugar, há o sentido metafórico. O fogo "consome" as cidades inimigas de Israel ( $\mathrm{Nm}$ 21:28). Em visão, o profeta "come" a palavra do Senhor (Jr 15:16; Ap 10:10). O ímpio "bebe" a iniquidade (Jó 15:16). Por sua vez, o sangue de Jesus é "verdadeira bebida" e sua carne é "verdadeira comida" (Jo 6:55). Nesse terceiro caso, o contato ou a compreensão de algo desconhecido ou misterioso é mediado pelas metáforas de comida e bebida.

3 Texto original: "Those who eat and drink together are by this very act tied to one another by a bond of friendship and mutual obligation".

4 Texto original: "The biblical texts that portray the sealing of a covenant by a communal act of eating and drinking bear the imprint of this primitive Semitic idea". 
A narrativa apocalíptica é marcada pelo uso de metáforas e símbolos. Na verdade, João diz que tudo que lhe foi "comunicado" o foi por meio de símbolos ou sinais (Ap 1:1). Ele emprega aí o verbo grego semanainô, também encontrado em Daniel 2:45 (na versão LXX) e em João 12:33: "Isto dizia, significando (semainon) de que gênero de morte estava para morrer" (ver Jo 21:18, 19). João utiliza no Apocalipse pelo menos dez diferentes verbos e três substantivos para narrar atividades relativas a comida e bebida. Alguns deles são: esthiô: "comer", "consumir" (Ap 2:7, 14, 20; 10:10; 17:16; 19:18), trefô: "alimentar", "nutrir", "sustentar" (Ap 12:6, 14), katesthiô: "tragar", "devorar”, "consumir” (Ap 10:9, 10; 11:5; 12:4; 20:9), chortazô: "alimentar", "saciar-se" (Ap 19:21), deipneô: "comer", "cear" (Ap 3:20), pinô: "beber" (Ap 14:10; 16:6; 18:3), dipsaô: "ter sede” (Ap 7:16;21:6; 22:17), karpos: "fruto" (Ap 22:1, 2. 6), limos: "fome", "apetite" (Ap 6:8; 18:8) e deipnôn: "banquete", "ceia” (Ap 19:9, 17).

As metáforas ou símbolos podem ser divididos em dois grupos principais, expressando respectivamente ideias de juízo e restauração.

Metáforas de juízo

Diversas imagens de comida e bebida são empregadas no Apocalipse com sentido negativo. Um primeiro sentido produzido pelas metáforas "comer" e "beber" no Apocalipse é o de juízo e condenação. $\mathrm{Na}$ narrativa dos selos há mensagens de juízo comunicadas por meio de símbolos relativos a comida e bebida. Aqueles que comem dos alimentos sacrificados aos ídolos assumem sociabilidade e companheirismo com os inimigos de Deus. Ao mesmo tempo, o beber do cálice da prostituição aponta para rompimento das relações com Deus e admissão de pertencimento e sociabilidade com os incrédulos.

Ao relatar o terceiro selo, João emprega vários símbolos para comunicar um sentido de fome. Falando do cavalo preto, ele descreve o cavaleiro com "uma balança na mão" e relata uma voz que anuncia preços inflacionados para "trigo" e "cevada", e adverte contra danificar o "azeite e o vinho" (Ap 6:6). No Antigo Testamento, considerado a fonte principal das metáforas do Apocalipse (ver BEALE, 2013; PAULIEN, 2004), trigo, óleo e vinho eram os alimentos básicos (Os 2:8, 22; Jl 2:19). Por sua vez, a imagem de balança e peso de comida comunica o sentido de fome e escassez (Lv 26:26; Ez 4:11, 16).

Nesse caso, o símbolo aponta para uma situação em que mesmo os alimentos básicos só estariam acessíveis a preços elevados. Entretanto, no 
contexto do Novo Testamento, o trigo é símbolo do evangelho, o óleo, do Espírito, e o vinho simboliza a graça (Mt 4:4; 13:3-10; Lc 8:11). Assim, o terceiro selo representa uma situação de fome, mas possivelmente não de pão, mas do pão espiritual, a Palavra da graça e do evangelho (Am 8:11-13).

Ao contrário do cavalo branco, que sugere abundância da oferta de salvação e do ministério da Palavra, o cavalo preto retrata um tempo de escassez do evangelho.

No emprego do verbo esthiô ("comer"), inicialmente João o utiliza de forma negativa, comunicando mensagens de condenação. Ele apresenta uma reprovação aos que comem "coisas sacrificadas aos ídolos" e que se "prostituem" (porneuô), seguindo a "doutrina de Balaão" (Ap $2: 14,20)$. O significado da metáfora precisa ser buscado no contexto do Antigo Testamento, de onde ele toma a narrativa de Balaão. Paulien (2004, p. 139) diz que "o propósito das alusões [intertextuais] é levar o leitor a considerar a passagem do AT em questão e aplicar seu significado à passagem do Apocalipse".

Segundo o relato do Antigo Testamento, as mulheres moabitas "por conselho de Balaão, fizeram prevaricar os filhos de Israel" (Nm 31:16). Após tentativas malsucedidas de amaldiçoar Israel, Balaão propôs ao rei moabita Balaque uma estratégia com o uso dos recursos femininos de sedução e idolatria. Com isso, os israelitas foram atraídos para um ritual pagão. Então comeram alimentos rituais (LXX, esthiô), se inclinaram aos ídolos e se prostituíram (ekporneuô) com as mulheres de Moabe (Nm 25:1, 2).

A proibição de "comer carnes sacrificadas aos ídolos" é afirmada em Atos 15:29, pelo concílio de Jerusalém, o qual retoma Levítico 15:7: "Nunca mais oferecerão os seus sacrifícios aos demônios, com os quais eles se prostituem; isso lhes será por estatuto perpétuo".

Osborne (2002, p. 144) propõe que a frase balein skandalon (Ap 2:14, "armar ciladas") indica levar alguém à apostasia. Em Mateus 18:7, a "pedra de escândalo" é uma tentação para romper as relações com Cristo; e em Romanos 9:33, ela se refere à rejeição de Jesus pelos judeus. Nesse caso, a expressão no Apocalipse pode indicar um tropeço ou tentação para romper relações de pertença e compromisso.

Paulo diz que "alguns [crentes], por efeito da familiaridade [synetheia, 'hábito', 'costume'] até agora com o ídolo, ainda comem dessas coisas como a ele sacrificadas". Mas depois diz: "Não é a comida que nos recomendará a Deus" (1Co 8:7, 8). Ele quer dizer, a exemplo do que 
afirma Isaías (ver Is 44:9-20), que os ídolos nada são e nada fazem. No entanto, juntar-se para comer à mesa com os que praticam a idolatria implica romper a relação de pertença e companheirismo cristão para associar-se a outra comunidade religiosa, nesse caso, pagã. Por isso, ele recomenda: "Fugi da idolatria [...] não quero que vos torneis associados [koinônos, 'companheirismo'] aos demônios [...] Não podeis beber o cálice do Senhor e o cálice dos demônios; não podeis ser participantes da mesa do Senhor e da mesa dos demônios" (1Co 10:14, 20, 21).

Portanto, a advertência feita às igrejas de Pérgamo e Tiatira (Ap $2: 14,20)$ não é exatamente acerca de comida e bebida, mas de associação e pertença religiosa. A prática de comensalidade é uma metáfora empregada para tratar de relações sociais e religiosas no contexto de pertencimento e companheirismo.

Ainda com um sentido negativo, o verbo esthiô é usado para afirmar que a meretriz Babilônia terá a "carne" comida e será queimada no fogo (Ap 17:16). João emprega aqui a palavra plural sarkas, que indica "porções de carne", sugerindo a imagem de feras que violentamente rasgam pedaços da carne de suas presas. A meretriz será odiada e morta pelos "reis da terra" e pela "besta" (Ap 17:16). Assim, a imagem de feras vorazes que dilaceram a carne de suas vítimas cria um quadro de extrema violência para retratar o destino da prostituta. Ela será destruída pela besta e os reis, seus antigos aliados (Ap 17:3, 12, 18), ou seus amantes, para usar a linguagem de Ezequiel de onde essa metáfora é tomada (Ez 23:25-30).

A metáfora retoma o juízo da antiga e apóstata Jerusalém, que seria desolada e teria a carne comida por seus antigos aliados (Ez 23:17, 19, 25). Retoma também o destino trágico de Jezabel (2Rs 9:30-37; ver Lv 21:9). Ela promovia a adoração a Baal (1Rs 16:29-31; 2Rs 9:30-32), e Elias predissera que seria devorada (LXX, katesthiô) por cães (1Rs 21:23). Os descendentes de Jeroboão também seriam comidos (esthiô) por cães e aves ( 1 Rs $14: 11 ; 16: 4 ; 21: 24)$.

Portanto, a imagem de corpos de vítimas expostos ao sol ou devorados por feras expressa a pior condição de indignidade, quando um sepultamento digno não era provido e o corpo ficava à mercê de animais selvagens e famintos. Esse foi o fim de Saul, até que recebeu um sepultamento providenciado pelos moradores de Jabes-Gileade (1Sm 10:10-13).

A mesma condição de condenação e destino trágicos é prevista para a besta e os reis da terra, os quais antes destroem a meretriz. Com o emprego do substantivo deipnon ("ceia", "comida"), o Apocalipse retrata uma "ceia" 
macabra em que novamente a "carne" (gr. sarx) de vítimas estará à mercê de aves e abutres. Assim, ele afirma que a "besta e os reis da terra" serão comidos pelas aves do céu, na chamada "grande ceia de Deus" (Ap 19:17-18).

No convite feito às aves, há uma ênfase na totalidade: "todas as aves" são chamadas (Ap 19:17, 21), e a "carne" provém de "reis, comandantes, poderosos, cavalos, cavaleiros", "carnes de todos, quer livres quer escravos” (Ap 19:18; ver Ap 6:15; 13:16; Ez 39:17). O juízo sobre os poderes antes oponentes ao povo de Deus é retratado com a metáfora de uma "ceia" provida por Deus às aves que "voam pelo meio do céu" (Ap 19:17), ou seja, as aves de rapina.

Mounce (1997, p. 358) diz que "permanecer insepulto para o prazer dos predadores era para os antigos um destino ignominioso. A cena é de desonra e destruição universal". Provan (1995, p. 117-118) diz que o fato de o cadáver ser comido por cães indica vergonha e indignidade pela falta de enterro digno e, "na crença do Antigo Oriente Médio, implicava a ausência dos restos mortais no além, nada ficando de sua memória". Tal será o destino da meretriz segundo o sentido produzido pelas metáforas apocalípticas.

Por fim, João emprega o verbo pinô ("beber") também numa mensagem de juízo, contra as pessoas seduzidas pela adoração aos ídolos nos últimos dias. Os "adoradores da besta e da sua imagem" beberão do "vinho da cólera de Deus, preparado sem mistura" (Ap 14:9; ver Ap 16:6; Ap 18:3). O autor emprega em Apocalipse 14:8 a mesma expressão de Apocalipse 14:10: tou oinou tou thumou ("o vinho da fúria") para falar dos pecados de Babilônia. Assim, os que bebem o "vinho da fúria de sua [da meretriz] fornicação" beberão o "vinho da cólera" de Deus (ver Ap 18:3).

Osborne (2002, p. 540) diz que "era comum misturar água ao vinho ao menos pela metade", pois "beber o vinho não diluído só ocorria quando a pessoa queria ficar embriagada”. A expressão indica que, nessa fase, os juízos de Deus já não buscam o arrependimento, mas a completa destruição dos condenados.

Novamente, a exemplo das metáforas de comida, a metáfora de beber vinho indica a atitude de compartilhar e tomar parte em certos pecados, nesse caso, de adoração e idolatria à besta. No segundo caso, a metáfora indica o participar ou compartilhar da punição pelo pecado da idolatria.

\section{Metáforas de restauração}

O Apocalipse segue a mesma estrutura dos profetas clássicos, em que mensagens de juízo e condenação são seguidas de anúncios de graça e restau- 
ração. Assim, as metáforas de comida e bebida também são empregadas no sentido positivo de redenção. Aqueles que comem e bebem podem também fazê-lo no propósito de reafirmar seu compromisso e pertencimento a Deus e a seu reino. Novamente, verbos e substantivos retratando práticas de comensalidade produzem o sentido de companheirismo e associação religiosa.

O verbo trefô ("sustentar", "nutrir", "prover", "alimentar") é empregado para retratar a condição da mulher pura que é "sustentada" por Deus no "deserto" por 1.260 dias (Ap 12:6, 14). Uma vez que a mulher e o deserto são simbólicos, o sustento provido é igualmente simbólico. A imagem descrita em Apocalipse 12 retoma a jornada dos israelitas no êxodo, quando Yahweh lhes proveu o maná (Êx 16:3, 4; ver mesmo verbo em Gn 48:15). Moisés diz: "Ele te humilhou e te deixou ter fome, e te sustentou com o maná [...] para entender que nem só de pão viverá o homem” (Dt 8:3,4).

$\mathrm{O}$ "sustento" para a mulher não é físico, mas espiritual. O deserto (eremos) simboliza não só lugar de prova, mas também de conforto e proteção divina (Êx 16:32; Dt 1:31; Sl 78:52; Os 2:14; Mc 1:13; Jo 6:31; At 7:36). A mulher como símbolo da igreja enfrenta provas e privações no deserto da perseguição, mas tem a garantia da provisão divina de conforto, proteção e salvação. Ao voltar do deserto, ela estará renovada e nutrida espiritualmente para prosseguir sua jornada.

Os verbos peinaô e dipsâ̂ ("ter fome", "ter sede") são empregados para falar da condição de completa satisfação por parte dos remidos no céu. Deus promete que eles nunca mais terão fome nem sede (Ap 7:16). $\mathrm{O}$ texto retoma a promessa de Jesus de que aqueles que vão a ele nunca mais terão fome nem sede (Jo 6:35; ver Jo 4:14; Jo 7:37; Mt 5:6).

A promessa é feita a uma audiência agrícola, cuja vida consistia na luta pela sobrevivência. O reino de Deus, descrito como um lugar de completa e permanente provisão de comida e bebida, era um forte atrativo para as populações carentes do antigo Oriente Médio, marcado por constantes secas e falta de alimentos básicos para a subsistência.

Mounce (1997, p. 166) diz que a promessa de não ter fome nem sede era "especialmente significativa nos tempos antigos quando essas coisas eram constantes ameaças. [Contudo,] a promessa vai além de simples privação física. Ela aponta para aquela satisfação final da mais profunda ansiedade da alma por plenitude espiritual".

Portanto, comida e bebida aqui, como as condições mais desejáveis, são metáforas para o estado de plenitude e satisfação a ser alcançado no reino de Deus. 
Por sua vez, o verbo deip deipneô ("cear", "comer") retrata uma situação de profunda intimidade. Jesus bate à porta de Laodiceia e faz a promessa de "cear" com quem abrir a porta (Ap 3:20). O verbo está relacionado ao substantivo deipnôn ("ceia", "comida"). Há uma progressão na metáfora: Jesus é um visitante à porta (socialidade ausente). Ele busca admissão. A pessoa abre a porta (socialidade). Então eles partilham a comida, numa ceia íntima (socialidade plena).

Osborne (2002, p. 213) diz que esta imagem de "cear" deriva das "práticas de comensalidade do Antigo Oriente Médio". Compartilhar a comida no mundo antigo equivalia a "compartilhar a vida". Quando pessoas estavam em desavença, "um convite para cear abria a porta para a reconciliação". A ceia, portanto, marca um evento de pacificação.

A condição de Laodiceia é melhor entendida quando se compara esta igreja com a meretriz a partir de ideia de falsa segurança. O povo de Laodiceia diz: "Estou rico e abastado e não preciso de coisa alguma", no entanto, é "pobre, cego e nu" (Ap 3:17). A meretriz diz: "Estou sentada como rainha. Viúva, não sou. Pranto nunca hei de ter" (Ap 18:7), e eis que num só dia sobrevêm seus flagelos: "morte, pranto e fome" (Ap 18:8). Jezabel, a mesma meretriz, ensina os crentes a "praticarem prostituição e a comerem coisas sacrificadas aos ídolos" (Ap 2:20). Nisso, ela entra para a ceia dos demônios e fecha a porta para Jesus. O fato de Jesus estar do lado de fora da porta de Laodiceia sugere certo paralelo no destino desta igreja com o destino da própria meretriz. Aquele que abre, renuncia à ceia dos ídolos e assume uma pertença com Jesus.

Este cear com Deus, disponibilizado a Laodiceia, aponta para a tão esperada "ceia" escatológica (Mt 26:29; Ap 19:9), no reino de Deus.

Por isso, o substantivo deipnon é também usado para descrever a "ceia" ou as "bodas" do Cordeiro com sua noiva (Ap 19:7, 9). Nisso, o Apocalipse retoma uma antiga predição profética. No Antigo Testamento, o Senhor prometeu um "banquete" em Sião, em que se servirão "pratos gordurosos com tutano e vinhos velhos bem clarificados", ocasião em que "tragará a morte para sempre" (Is 25:6-8). A menção a "gordura", proibida para consumo (Lv 7:23-25), e "vinho", proibido em certas oca-

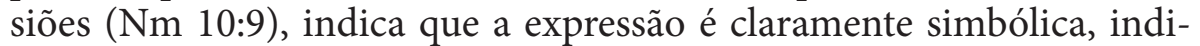
cando condições de fartura e plenitude. Mounce (1997, p. 348) diz que "a promessa antecipa as alegrias do banquete messiânico que celebrará a tão esperada cerimônia das bodas do Cordeiro com sua igreja".

A ceia escatológica com pratos "gordurosos" e "vinhos velhos" é uma eloquente metáfora da completa restauração final, ocasião em que o distan- 
ciamento entre Deus e sua criação deve ser para sempre superado. Quando o filho pródigo volta para casa, o pai lhe oferece um banquete com um "novilho cevado" (Lc 15:23). Os pecadores remidos serão igualmente recebidos à mesa da ceia de Deus, uma poderosa metáfora para falar de completa restauração de relacionamentos e fim de desavenças entre Deus e sua criação.

Ainda na carta à igreja de Éfeso, o Apocalipse emprega o verbo esthiô, agora de forma positiva, para anunciar que os "vencedores" vão se alimentar da "árvore da vida" que se encontra no "paraíso de Deus" (Ap 2:7), uma referência ao jardim do Éden (ver Gn 3:22; Ap 22:2, 14). Aquele que abre a porta e ceia com Jesus é contado como vencedor e terá acesso à arvore da vida, para se alimentar da vida eterna (Ap 3:20).

Segundo o relato de Gênesis, após o pecado, uma espada flamejante foi posta para proteger a árvore da vida, a fim de que Adão e Eva não comessem do fruto e adquirissem a imortalidade, em pecado (Gn 3:2224). No novo Éden os vencedores têm livre acesso à "árvore da vida" (2:7; $22: 14)$ e podem beber da fonte da água da vida $(21: 6 ; 22: 1,17)$. A metáfora indica a restauração do direito e do acesso à imortalidade. Tudo que o homem perdeu no paraíso terrestre é restaurado no celestial.

No paraíso dos remidos, a árvore da vida produz o "fruto" da vida. O substantivo karpos, usado no Apocalipse para descrever esse "fruto" (21:2), é empregado sete vezes no texto grego de Gênesis 1 a 4 . A terminologia comum sugere que o autor do Apocalipse pretende retomar a memória do paraíso perdido e do fruto tornado inacessível após a queda.

Há um paralelismo linguístico entre os dois textos, enfocando o rio que flui para regar a árvore da vida:

1. Apocalipse 22:1, 2 - “o rio da água da vida [...] sai do trono de Deus e do Cordeiro" para regar a árvore da vida que produz "doze frutos".

2. Gênesis 2:10 - "um rio saía [...] do Éden para regar o jardim”.

3. potamon [...] ekporeuomenon ek tou tronou tou theou kai tou arnion.

4. potamos de ekporeuetai ek edem.

A imagem descrita no Apocalipse traz engastado também o texto de Ezequiel 47:12, em que um "rio" (potamou) "sai" (ekporeuetai) "do 
santuário" (ek ton hagion) e rega árvores cujos frutos servem de alimento e cujas folhas curam os povos. Sloan e Newman (2002, p. 58-59) afirmam que "o engaste de fragmentos, imagens e ecos de um texto dentro de outro" é uma prática comum na literatura do Novo Testamento.

Com essa linguagem, mediada por Ezequiel, o Apocalipse reconstrói o texto de Genesis 1 a 3, apontando a restauração de todas as coisas no "novo céu" e "nova terra" em termos de livre acesso à água da vida e ao fruto da árvore da vida. Isso lembra a definição de Julia Kristeva (1969, p. 64) de que "todo texto se constrói como um mosaico de citações, todo texto e absorção e transformação de um outro texto". O Apocalipse é construído como um mosaico dos textos do Antigo Testamento, os quais são ressignificados ou reaplicados ao fim e restauração de todas as coisas no reino de Deus.

Assim, o texto de Apocalipse 22 retrata a humanidade redimida de volta ao jardim do Éden, livre para comer do abundante fruto da árvore da vida (Ap 22:1-2). Adão e Eva não puderam mais comer da árvore da vida, mas os remidos terão acesso à arvore e seus frutos, e as folhas servirão para "cura" das nações (Ap 22:2). A maldição terá sido removida (ver Ap 22:3; Gn 3:14-24), toda desavença entre Deus e sua criação terá sido para sempre superada, e o povo de Deus terá novamente o privilégio de "ver a sua face" (ver Ap 22:4; Gn 3:8).

$\mathrm{O}$ alimentar-se da árvore da vida, que é regada pelo rio da vida que sai do trono de Deus, ou do santuário na linguagem de Ezequiel, significa que os remidos vão alimentar-se da própria presença de Deus, cuja face eles verão novamente. Assim, a metáfora de comida e bebida descreve condições de restauração de relações e renovação de compromisso e pertencimento. $\mathrm{O}$ relacionamento divino-humano será completamente restaurado. Mounce (1997, p. 72) diz que "o paraíso de Deus no Apocalipse simboliza o estado escatológico em que o perfeito relacionamento entre Deus e sua criação é restaurado à condição de antes do pecado".

Kristemaker (2001, p. 580) lembra que "a revelação divina começa com Adão e Eva no paraíso, com a árvore da vida e o rio para regar o jardim, e finaliza com um quadro dos remidos em que um jardim renovado, com a árvore da vida e o rio da vida fluindo do trono de Deus e do Cordeiro". "Vida flui do trono de Deus de forma incessante no novo mundo" (JOHNSON, 1981, p. 599).

Beale (2013, p. 1104) comenta que "a água da vida é uma representação da vida eterna e tem sua origem em Deus e no Cordeiro”. Embora 
“o Espírito Santo possa estar em mente, a metáfora da água primariamente representa a vida de eterno companheirismo com Deus e Cristo".

Assim, o direito à fonte da vida, perdido por Adão, é devolvido aos que ceiam com Jesus.

\section{Considerações finais}

O amplo uso das metáforas comer e beber conectam intertextualmente o Apocalipse ao Gênesis e a todo o Antigo Testamento, permitindo a visão de que essa linguagem simbólica atravessa todo o conjunto do texto bíblico. Metáforas descritivas da atitude de se sentar à mesa e comer dos alimentos oferecidos aos ídolos e beber do vinho da prostituição produzem o sentido de juízo, condenação e completa destruição por causa do rompimento das relações com Deus.

Por outro lado, há metáforas com o sentido positivo de restauração e redenção. O Gênesis começa com o relato de que a criação perdeu o elo com o Criador ao comer da árvore da ciência do bem e do mal, não podendo mais comer da árvore da vida $(\mathrm{Gn} 3: 11,22)$. No evangelho Jesus chama os discípulos a comer a sua "carne" e beber o seu "sangue" (Jo 6:55).

O Apocalipse mostra Jesus batendo à porta, para entrar e cear com quem abrir. E finaliza com a imagem da livre participação e o franco acesso dos filhos de Deus às fontes da vida imortal.

Esta é uma eloquente metáfora para falar aos leitores originais da completa restauração de todas as coisas no novo Éden planejado por Deus para receber sua criação de volta para casa.

\section{Referências}

BEALE, G. K. The book of Revelation. Grand Rapids: Eerdmans, 2013. (The New International Greek Testament Commentary)

GARCIA, P. R. Isto é o meu corpo: rituais de alimentação e interação social no cristianismo primitivo. Revista Caminhando, v. 12, n. 20, p. 19-28, 2007.

JOHNSON, A. F. Revelation. Grand Rapids: Zondervan, 1981. (The Expositor's Bible Commentary). 
KLINGBEIL, G. As metáforas "comer" e "beber": um estudo sobre o pensamento e a teologia apocalíptica neotestamentários". In: TIMM, A.; RODOR, A. A.; DORNELES, V. (Eds.). O Futuro: A visão adventista dos últimos acontecimentos. Engenheiro Coelho: Unaspress, 2004.

KRISTEMAKER, S. Revelation. Grand Rapids: Baker Academic, 2001. (New Testament Commentary)

KRISTEVA, J. Introdução à Semanálise. São Paulo Perspectiva, 1969.

LAKOFF, G.; JOHNSON, M. Metaphors We Live By. Londres: University Chicago Press, 2003.

LÉVI-STRAUSS, C. Totemism. Harmondsworth: Penguin, 1969.

MACDONALD, N. Not Bread Alone: the uses of food in the Old Testament. New York: Oxford University Press, 2008.

MOUNCE, R. H. The Book of Revelation Revised. Grand Rapids: Eerdmans, 1997. (The New International Commentary on the New Testament)

OSBORNE, G. R. Revelation. Grand Rapids: Baker Academic, 2002. (Baker Exegetical Commentary on the New Testament)

PAULIEN, J. The Deep Things of God. Hagerstown: Review and Herald, 2004.

PROVAN, I. W. 1 and 2 Kings. Peabody: Hendrickson, 1995. (New International Biblical Commentary)

SLOAN, R. B.; NEWMAN, C. C. Ancient Jewish hermeneutics. In: CORLEY, B.; LEMKE, S. W. E.; LOVEJOY, G. I. (Eds.). Biblical Hermeneutics: a comprehensive introduction to interpreting scripture. 2. ed. Nashville: Broadman \& Holmas, 2002. 